\title{
Jean-Francois Marmontel, Mémoires
}

\section{Elena Aschieri}

\section{OpenEdition}

\section{Journals}

Édition électronique

URL : http://journals.openedition.org/studifrancesi/7947

DOI : 10.4000/studifrancesi.7947

ISSN : 2427-5856

\section{Éditeur}

Rosenberg \& Sellier

\section{Édition imprimée}

Date de publication : 1 juillet 2009

Pagination : 405

ISSN : 0039-2944

\section{Référence électronique}

Elena Aschieri, « Jean-Francois Marmontel, Mémoires », Studi Francesi [En ligne], 158 (LIII | II) | 2009,

mis en ligne le 30 novembre 2015, consulté le 07 janvier 2021. URL : http://journals.openedition.org/ studifrancesi/7947 ; DOI : https://doi.org/10.4000/studifrancesi.7947

Ce document a été généré automatiquement le 7 janvier 2021.

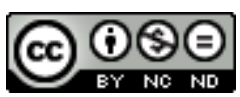

Studi Francesi è distribuita con Licenza Creative Commons Attribuzione - Non commerciale - Non opere derivate 4.0 Internazionale. 


\title{
Jean-Francois Marmontel, Mémoires
}

\author{
Elena Aschieri
}

\section{RÉFÉRENCE}

JEAN-FRAnCoIS MARmontel, Mémoires. Edition critique par John Renwick, Paris, Champion, 2008, pp. 873.

1 Marmontel n'est décidément plus dans l'oubli où il avait sombré au XIX et pour une bonne partie du $\mathrm{xx}^{\mathrm{e}}$ siècles, victime de préjugés politiques voire personnels et de l'évolution du goût. Depuis une trentaine d'années, en effet, les études sur cet homme de lettres se sont multipliées. Une ultérieure démonstration de l'intérêt que l'«enfant gâté de l'Ancien Régime», selon l'appellation de F. Aulard, suscite aujourd'hui est la nouvelle édition critique de ses Mémoires présentée par J. Renwick, remaniée et augmentée par rapport à celle qu'il avait déjà établie en 1972 et à laquelle avait suivi, en 1999, celle de J. P. Guicciardi et de G. Thierriat. Le texte de base demeurant, par ailleurs, toujours celui de la première édition, parue chez Xhrouet, de 1804.

2 L'Introduction (pp. 11-90) présente l'œuvre à partir de sa genèse. Renwick souligne à plusieurs reprises qu'on ne peut pas être très précis vis-à-vis des dates de la rédaction du texte mais que, sans doute, le manuscrit fut achevé «en très grande partie, et au plus tard, vers le mois de décembre 1796» (p. 17); une petite histoire du manuscrit, qui est d'ailleurs difficile à reconstruire avec exactitude, est également tracée. Renwick esquisse, ensuite, le caractère et la mentalité de Marmontel à l'usage du lecteur de ces Mémoires «qui, tout en révélant si bien le xviII ${ }^{e}$ siècle révèlent aussi la personnalité d'un homme qui fut remarquablement adapté à son époque, dont il incarna les défauts intellectuels, moraux et littéraires ainsi que les qualités aimables» (p. 26). Renwick, dans un ample panorama (pp. 26-79), reconstruit la mentalité de Marmontel, s'attardant sur les rapports intellectuels et sociaux qui ressortent des Mémoires. Il étudie les liens entre Marmontel et les salons parisiens, qui ont été le vrai cadre de l'activité de l'honnête homme mondain; il souligne les rapports difficiles et d'incompréhension avec Rousseau; il met en évidence les réactions du mémorialiste 
vis-à-vis de la Révolution. Un paragraphe, limpide et intéressant, est consacré à la langue et au style des Mémoires. Une bibliographie fort exhaustive des éditions existantes et des études critiques fondamentales, ainsi qu'une ponctuelle Biographie, définie avec modestie, sommaire (pp. 93-110), concluent enfin l'Introduction au texte des Mémoires, outil indispensable pour tout dix-huitièmiste. 